\title{
LA-UR-17-21904
}

Approved for public release; distribution is unlimited.

Title: $\quad$ Space Nuclear Reactor Development

Author(s): $\quad$ Mcclure, Patrick Ray

Intended for: Nuclear Engineering Capability Review

Issued: 2017-03-06 
Disclaimer:

Los Alamos National Laboratory, an affirmative action/equal opportunity employer, is operated by the Los Alamos National Security, LLC for the National Nuclear Security Administration of the U.S. Department of Energy under contract DE-AC52-06NA25396. By approving this article, the publisher recognizes that the U.S. Government retains nonexclusive, royalty-free license to publish or reproduce the published form of this contribution, or to allow others to do so, for U.S. Government purposes. Los Alamos National Laboratory requests that the publisher identify this article as work performed under the auspices of the U.S. Department of Energy. Los Alamos National Laboratory strongly supports academic freedom and a researcher's right to publish; as an institution, however, the Laboratory does not endorse the viewpoint of a publication or guarantee its technical correctness. 


\section{Space Nuclear Reactor Development}

Nuclear Engineering Capability Review

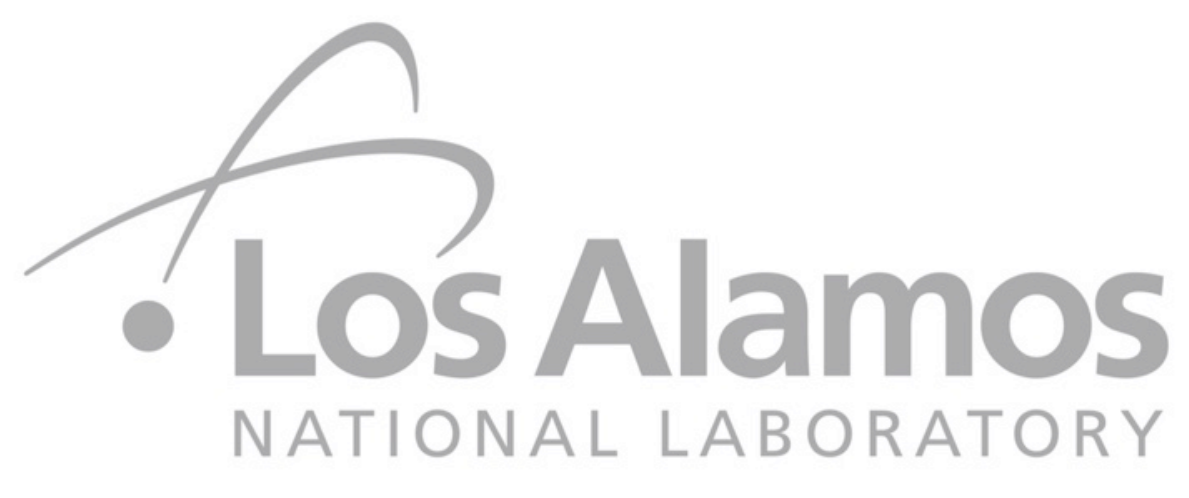

Patrick McClure, NEN-5

March, 2017 


\section{The KiloPower Space Reactor Concept}
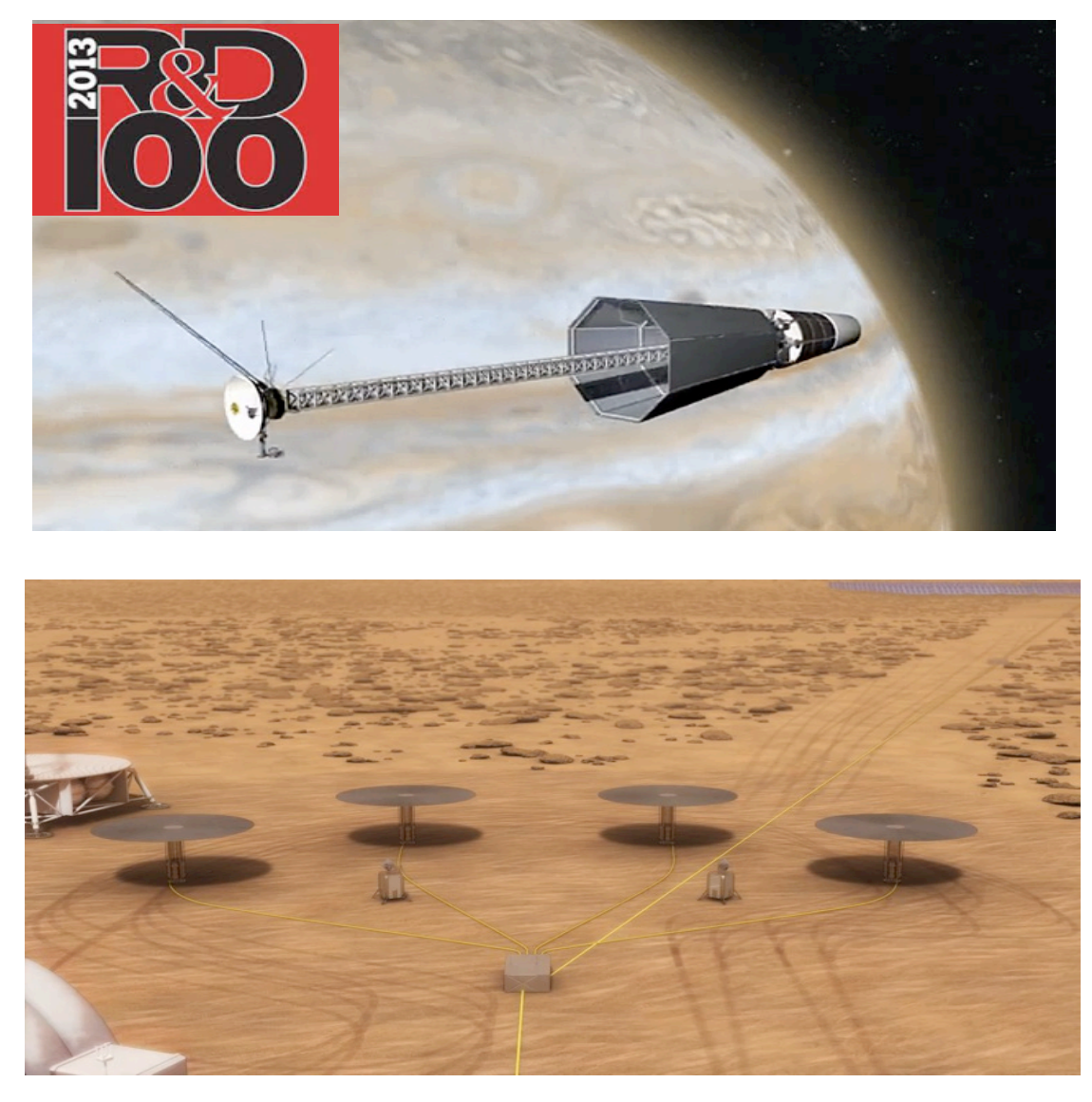

Los Alamos National Laboratory

\section{Attributes:}

- Scalable 1-10kWe (4-10kWt)

- All Passive Heat Transfer

- Stirling Power Conversion

- UMo cast metal fuel

- Low Fuel Burnup

- Low startup power

- Start/Stop operation

\section{Benefits:}

- Lower Reoccurring Costs

- Safer Launches

- Higher Power Missions

- Longer Missions

- Extreme Environments

- Nuclear Electric Propulsion

- Destination Startup
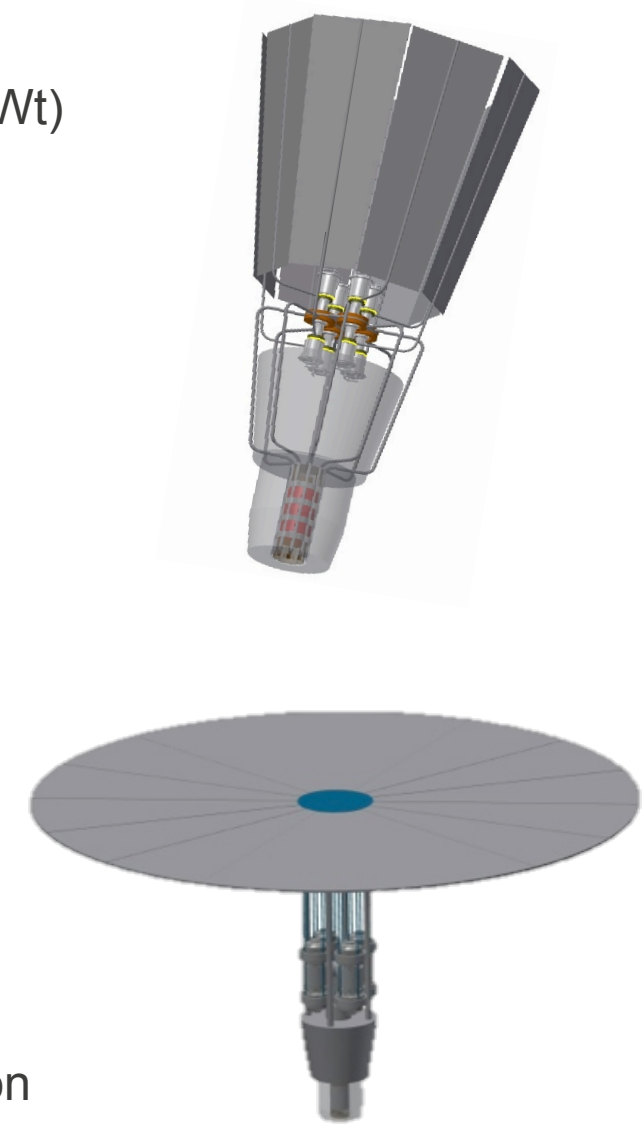


\section{KiloPower Fills Gap in Nuclear Portfolio}

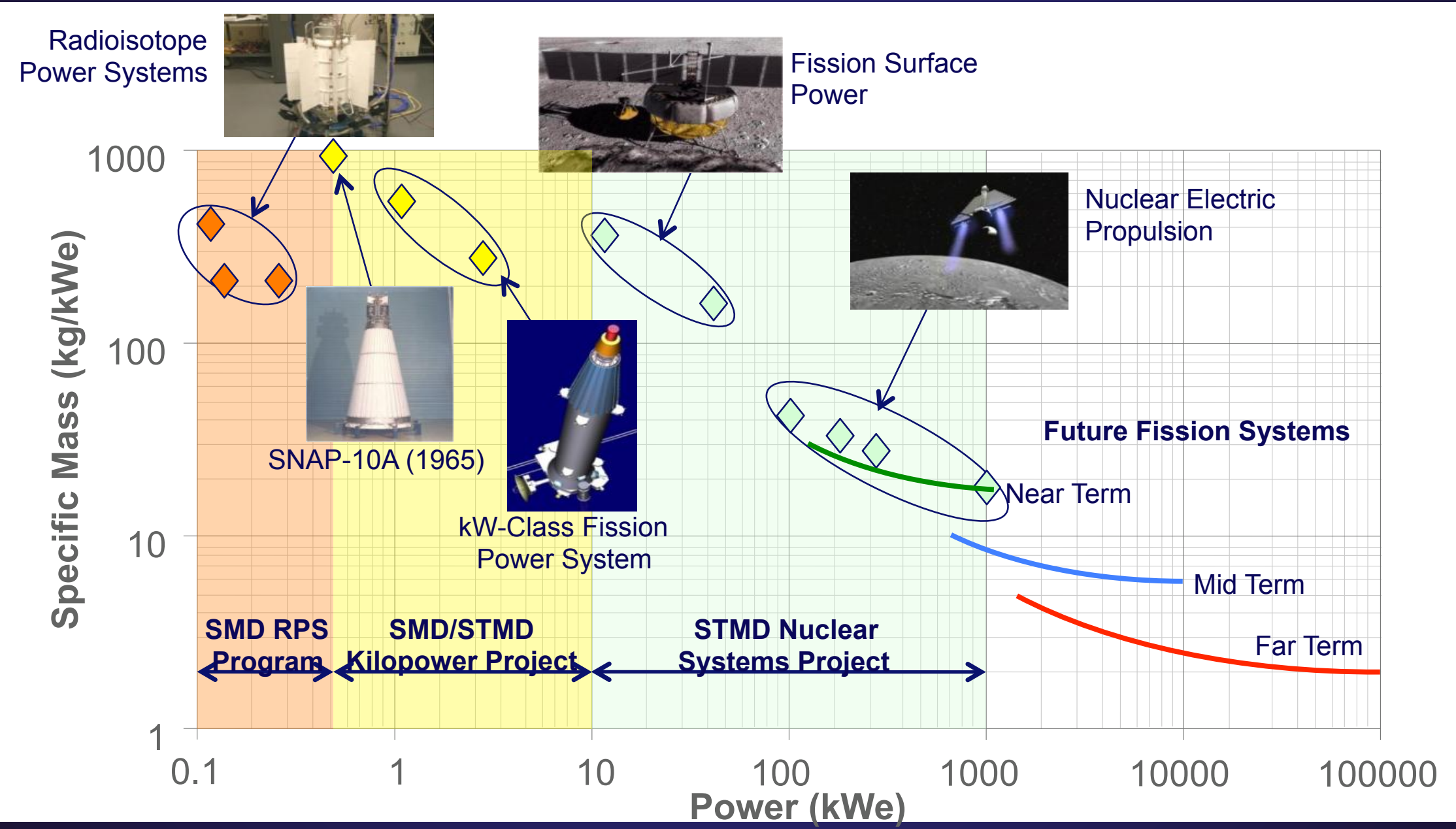




\section{Latest Proposed Missions (latest NASA mission planning)}

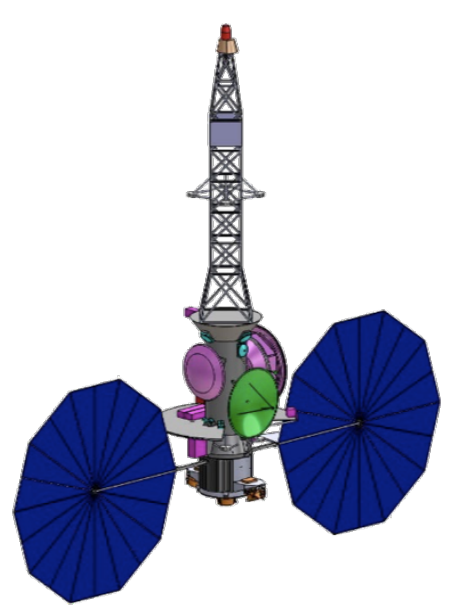

Titan Saturn System Mission spacecraft with attached $1 \mathrm{~kW}$ fission reactor
Chiron Orbiter spacecraft with

$8 \mathrm{kWe}$ reactor and Nuclear

Electric Propulsion (NEP)

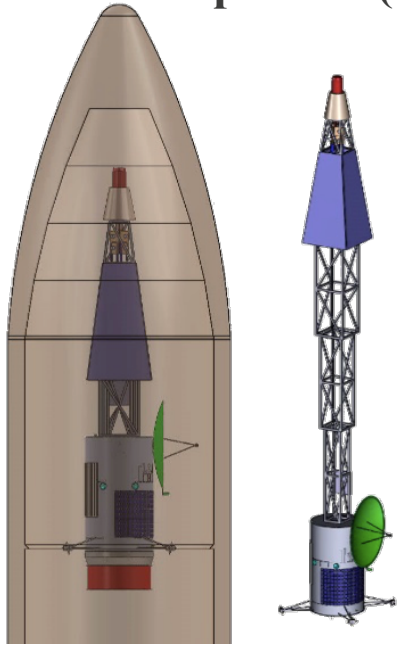

Kuiper Belt Object Orbiter spacecraft with $10 \mathrm{kWe}$ reactor and Nuclear Electric Propulsion (NEP)
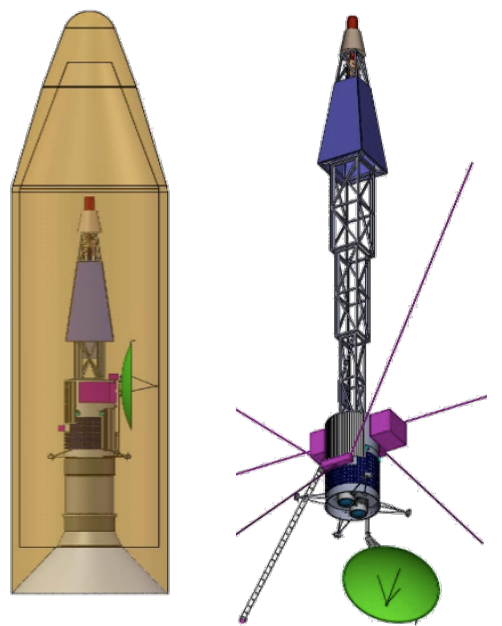
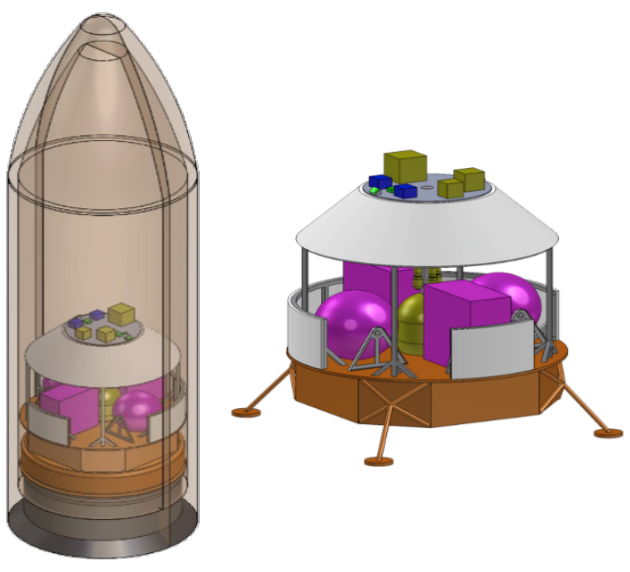

Mars ISRU fission powered lander concept in $\mathrm{LV}$ left, and deployed on Martian surface right 


\section{Why this reactor design?}

- Very simple, reliable design

- Self-regulating design using simple reactor physics

- No measurable nuclear effects

- Small temperature gradients and stresses, and high tolerance to any potential transient

- Available fuel with existing Infrastructure

- Uranium alloy (U-Mo) cast and machined by Y-12 Plant

- Heat pipe reactors are simple, reliable, and robust

- Eliminates components associated with pumped loops; simplifies integration

- The only reactor startup action is to withdraw reactivity control

- Systems use existing thermoelectric or Stirling engine technology and design

- Low cost testing and demonstration

- Non-nuclear system demonstration requires very little infrastructure and power.

- Nuclear demonstration accommodated in existing facility like those at NCERC.

- Safe to Launch!

- A reactor that has not undergone fission will have from 1 to 10 's of curies of naturally occurring radioactivity

- This is 1,000 s to 10,000 s times lower radioactivity than in current radioisotope systems 


\section{DUFF: A "Critical" Starting Point}

- Proof-of-Concept Test

- Test Configuration

- Highly Enriched Uranium core with central hole to accommodate heat pipe

- Heat transfer via single water heat pipe

- Power generation via two opposed free-piston Stirling Engines

\section{- Significance}

- First-ever heat pipe cooled fission experiment

- First-ever Stirling engine operation with fission heat

- Demonstration of nuclear reactivity feedback with prototype components

\section{- Test Objectives}

- Use electric power generated from nuclear heat to power a load

- Demonstrate that basic reactor physics was well characterized and predictable using current analytic tools

\section{LDRD Funded - Lab investing in technology}




\section{Technology Development Strategy}

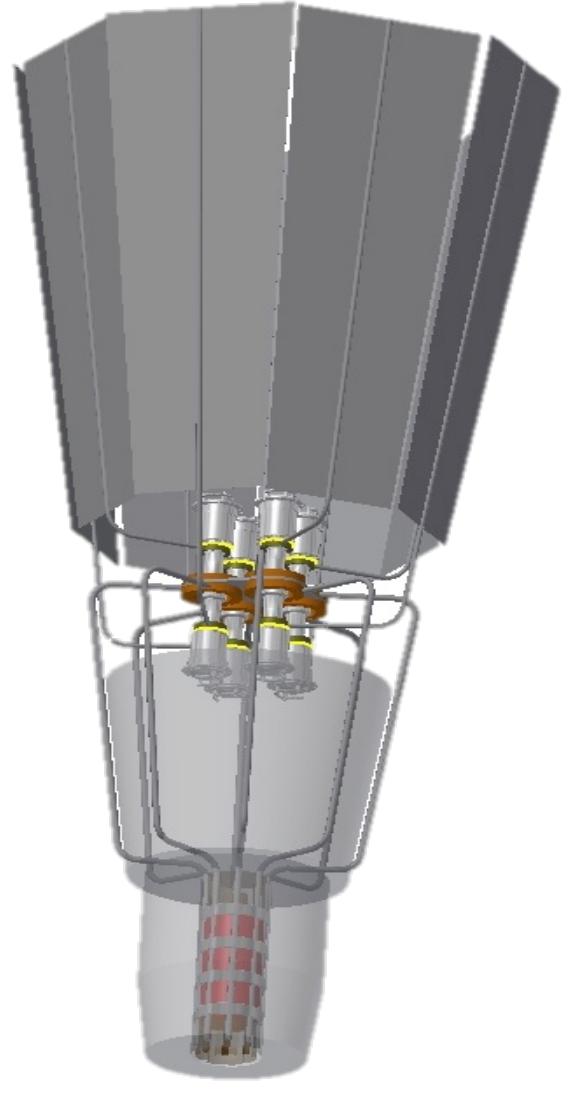

Flight Concept

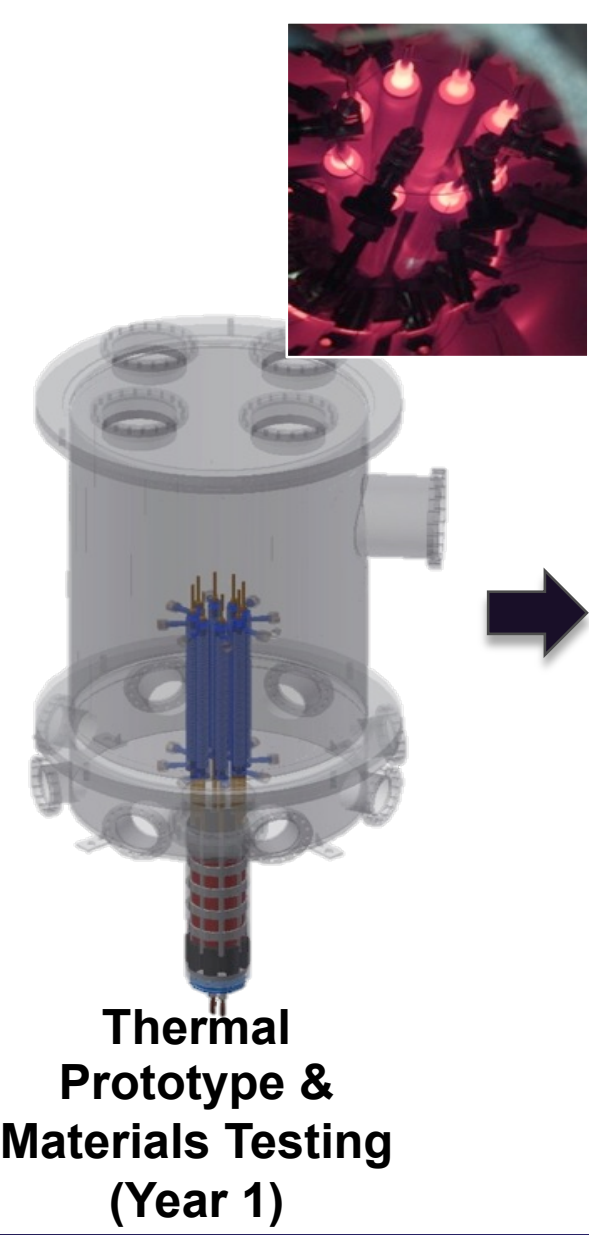

(Year 1)

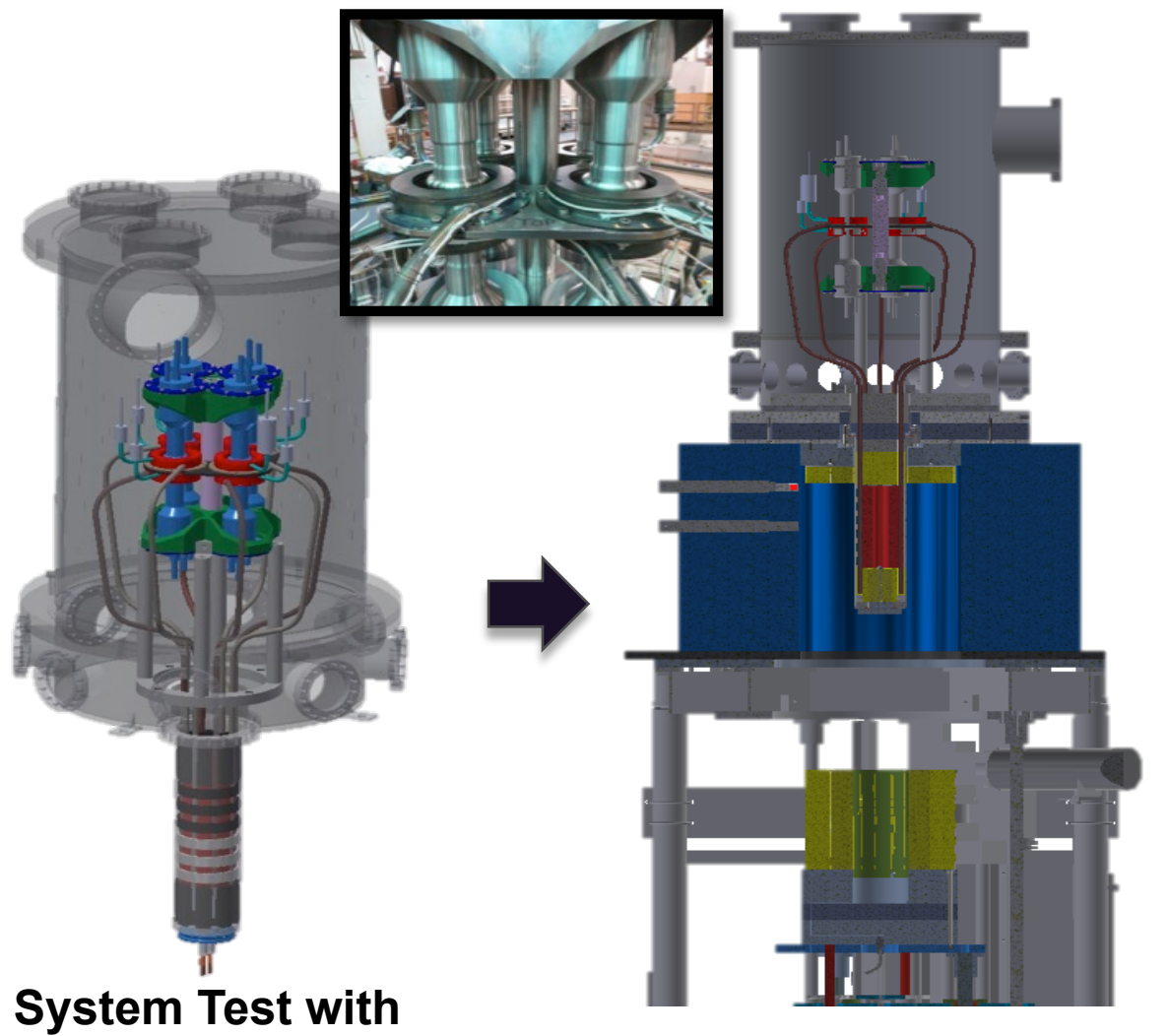

Reactor Experiment with HEU Core (Year 3) 


\section{KiloPower Nuclear-Powered Test}

(at the Nevada Test Site)

- Kilopower Reactor Using Stirling TechnologY

- Nuclear test of 1-kWe system at NNSA Device Assembly Facility.

- Extensive electrical testing of system underway at NASA

- Replaces HEU fuel with DU (depleted in U235)

- Electrical heater provides simulates fission power and feedback

- Addresses

1. Neutronics/Criticality

2. Reactor power/feedback

3. Heat transfer and thermal balance

4. Startup/shutdown/control operations

5. Operational stability and robustness to system offsets

6. Converted electrical power and efficiency

7. Exercises/demonstrates required flight-like infrastructure

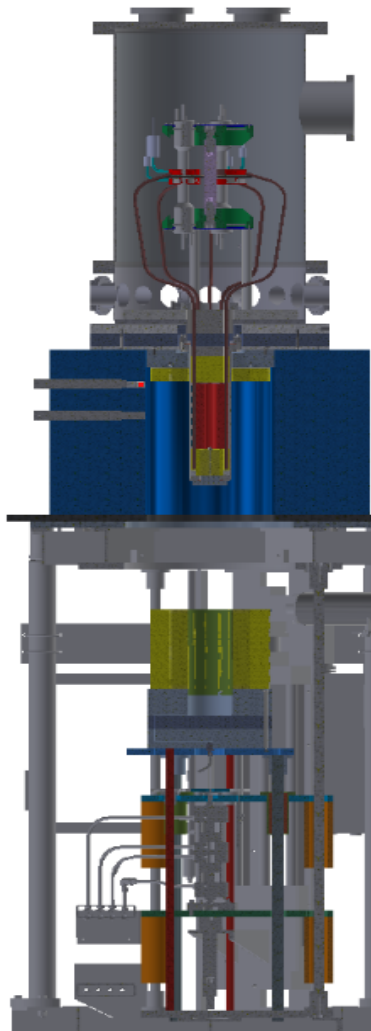

Reflector (yellow) fully withdrawn leaving fuel (red) and SS shielding (blue) in highly subcritical state 


\section{KRUSTY REACTOR CONFIGURATION}

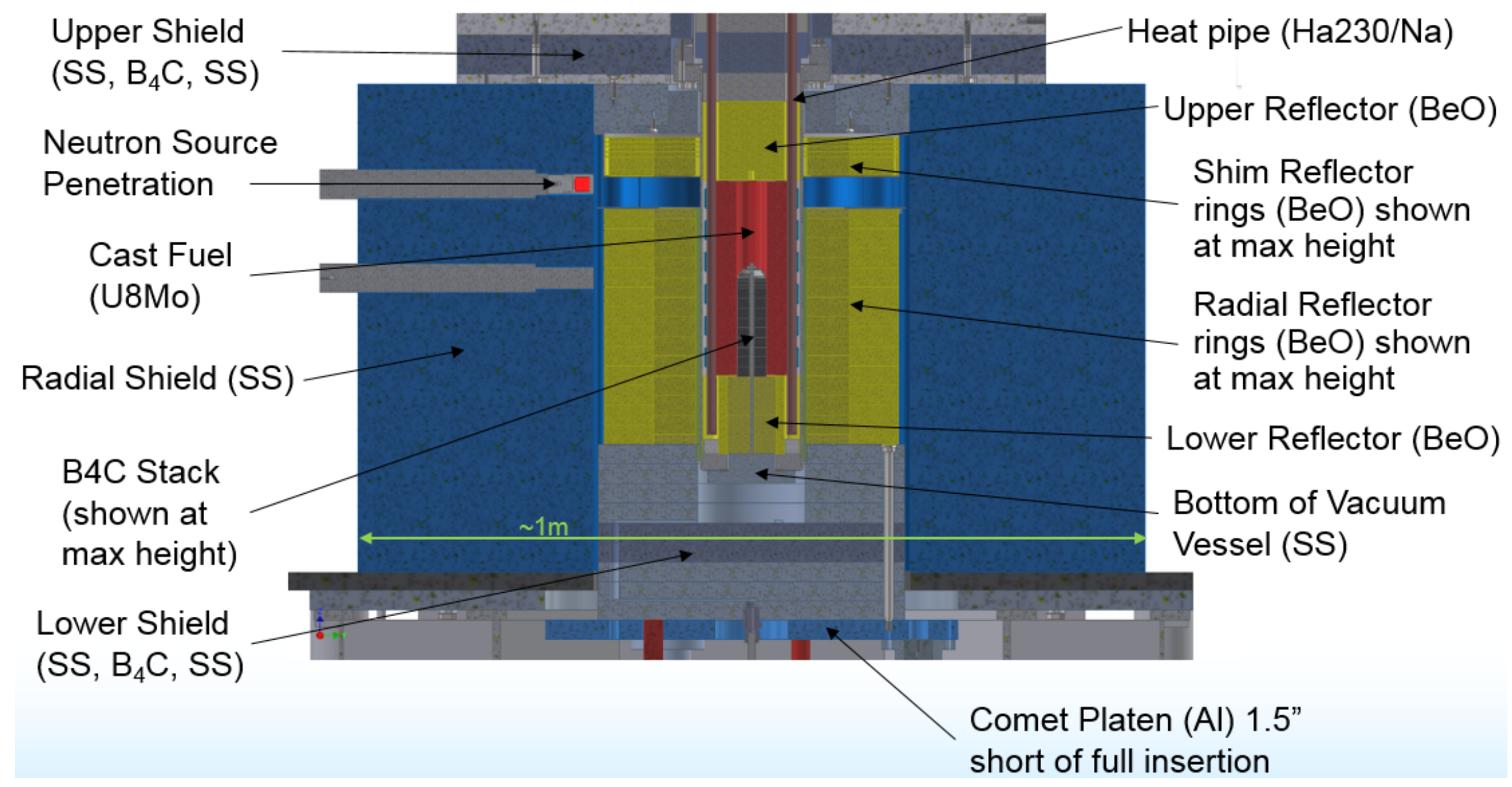




\section{Platen Positions}

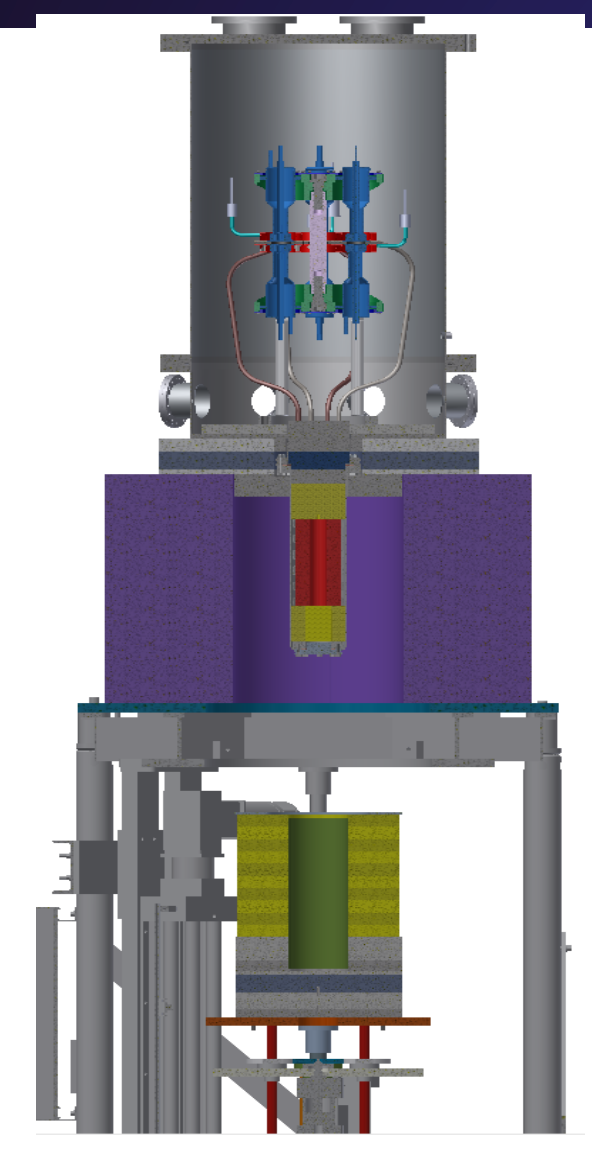

Fully Withdrawn

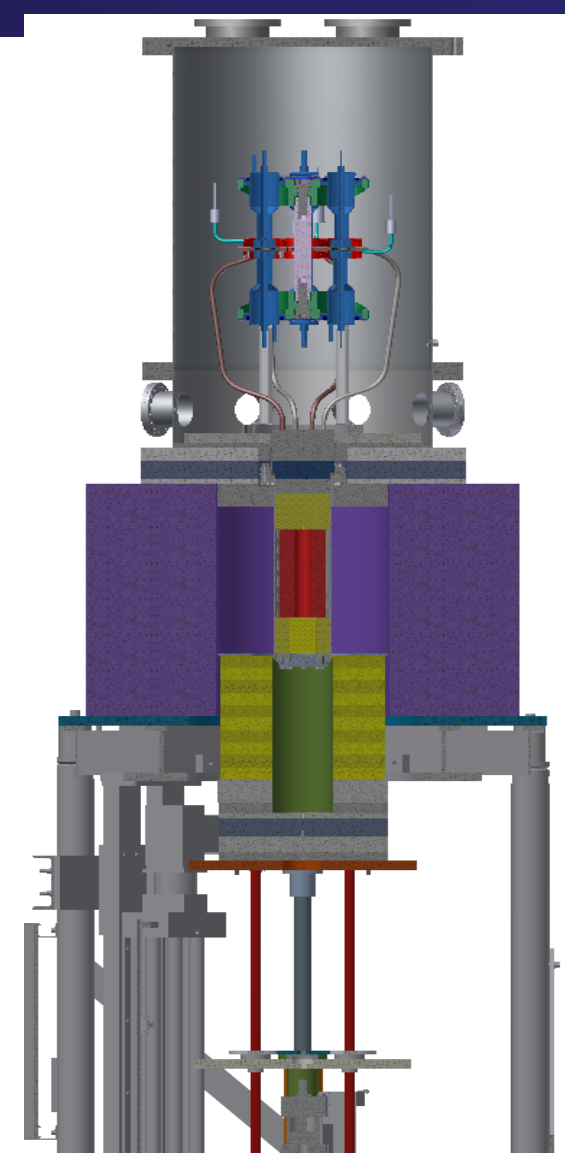

Neutronically withdrawn

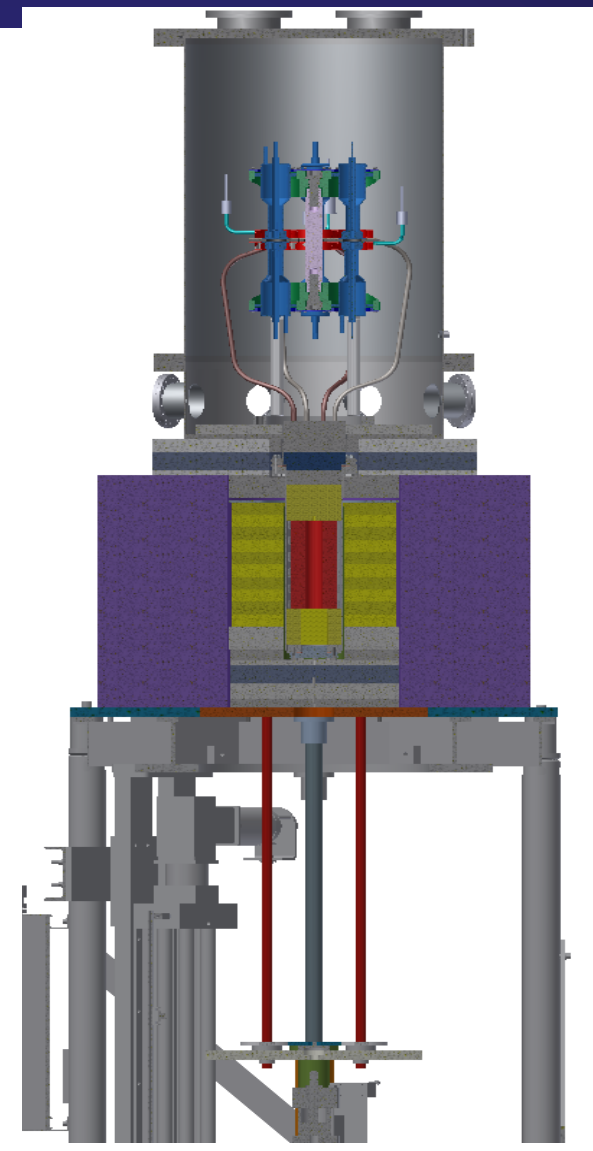

Fully Inserted

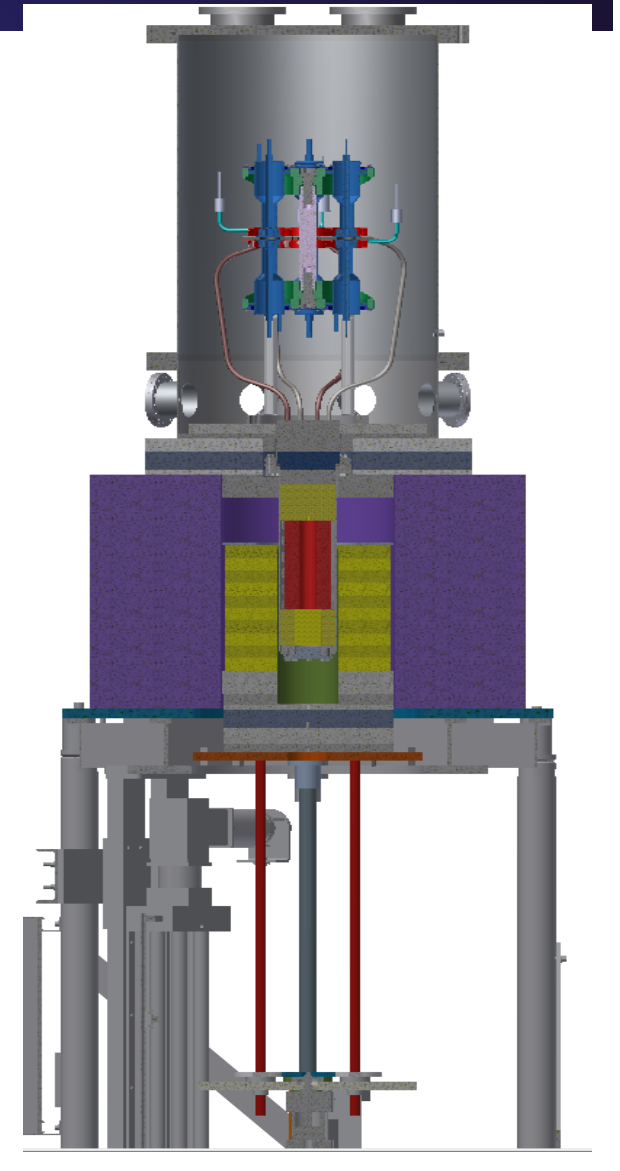

Hydraulic scram from full insertion 


\section{KRUSTY Hardware}

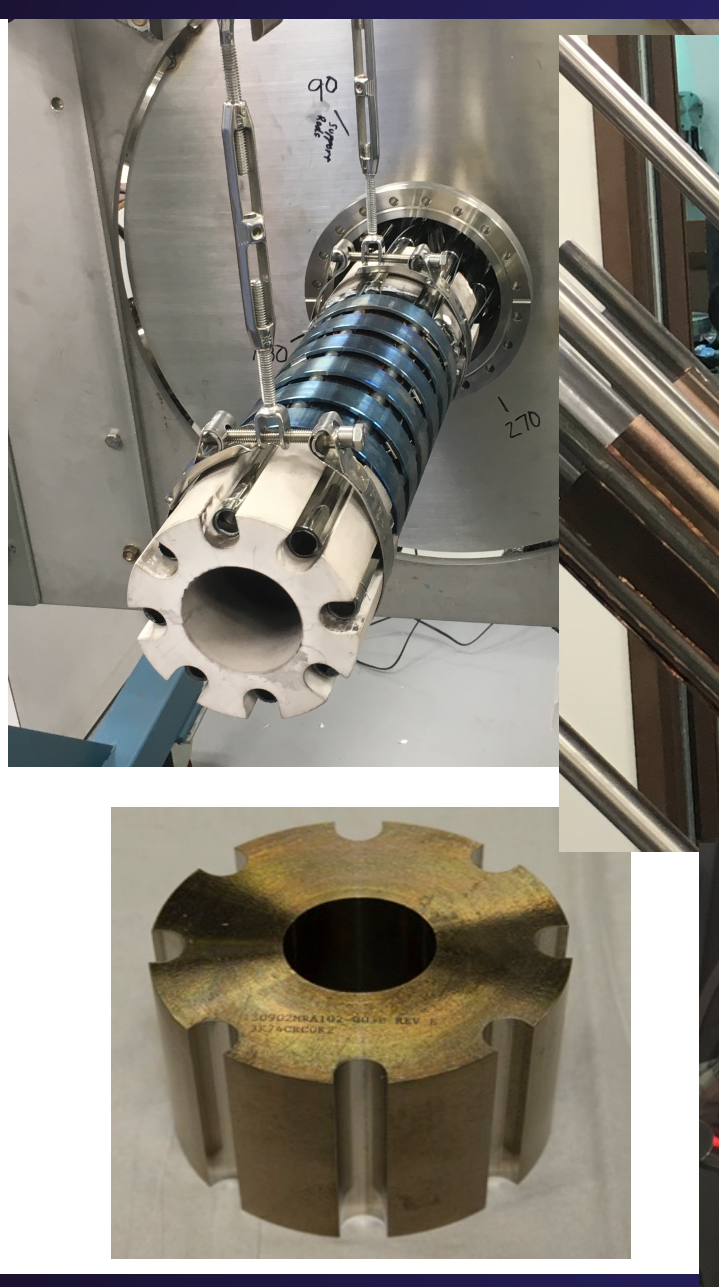

Los Alamos National Laboratory
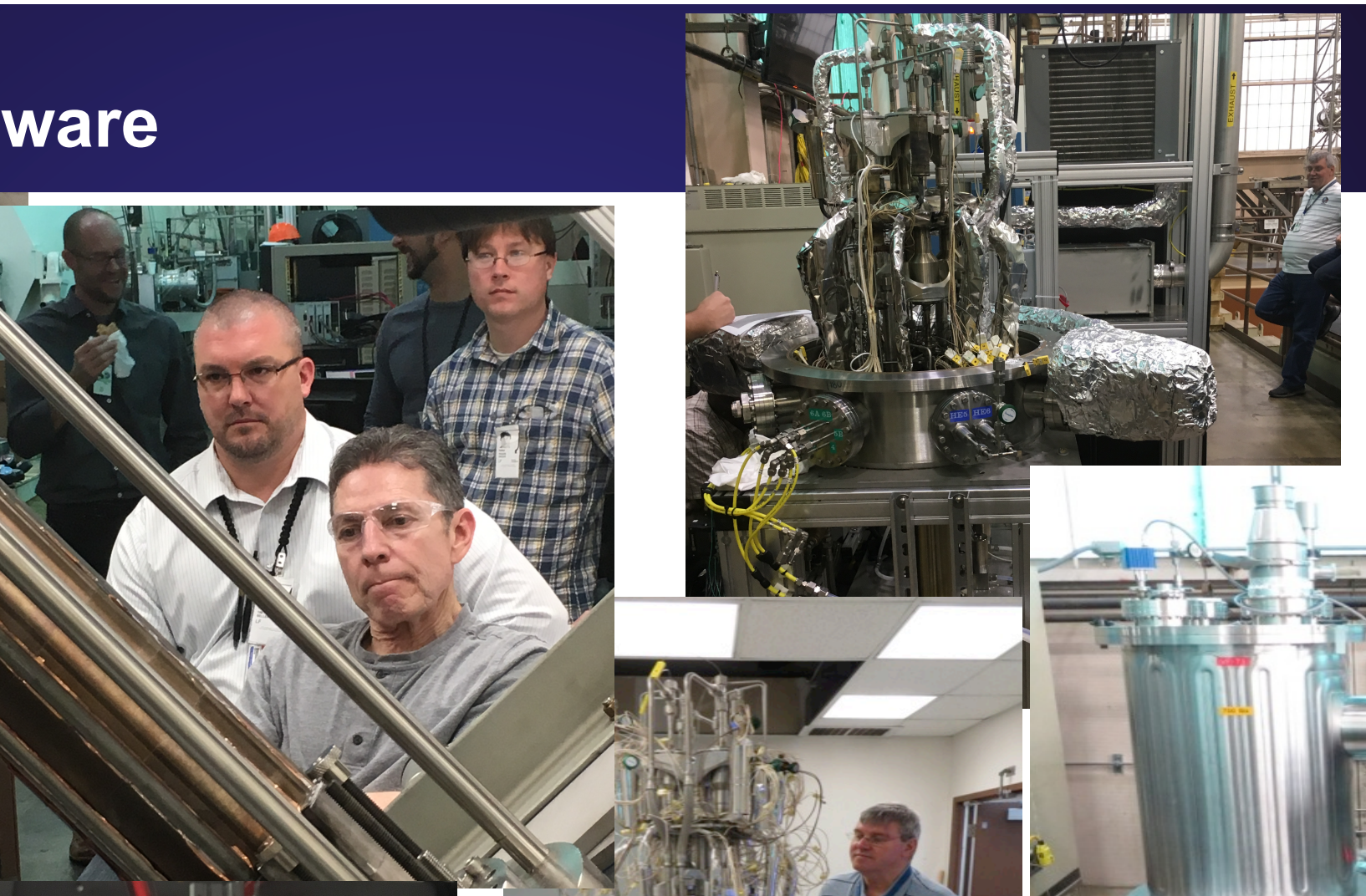


\section{$1 \mathrm{~kW}_{\mathrm{e}}$ KRUSTY Test Retires Many Challenges for $10 \mathbf{k W}_{\mathrm{e}}$ System}

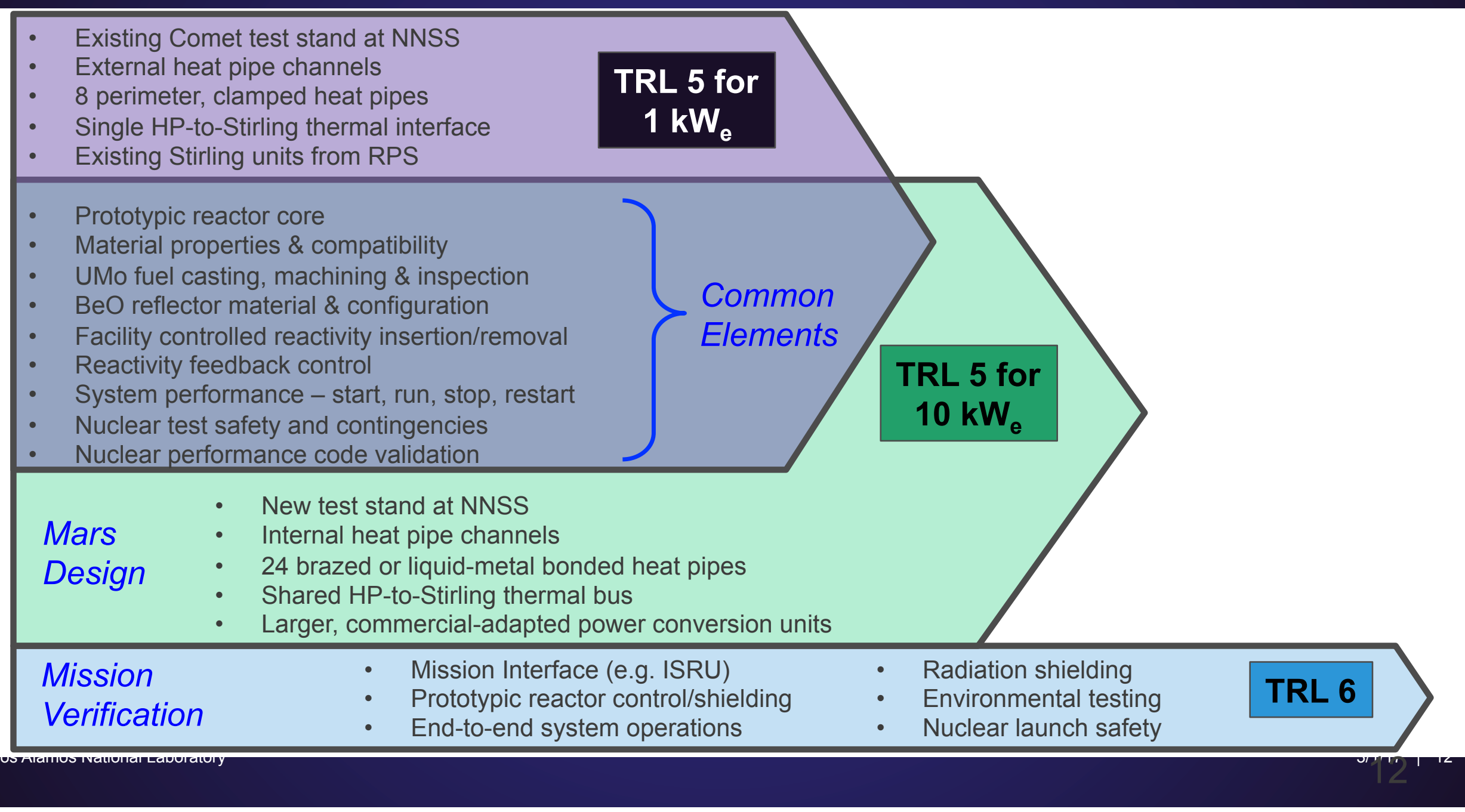




\section{Cross sectional view of proposed Kilopower cores (each schematic is $16 \times 16 \mathrm{~cm}$ )}

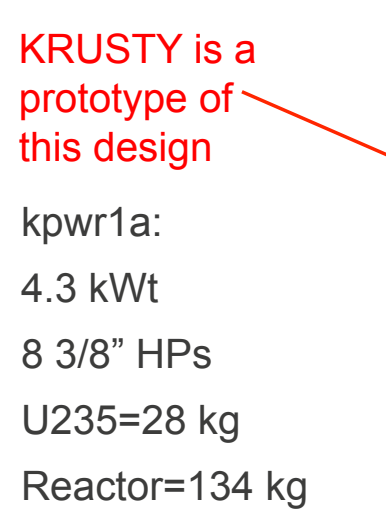

kpwr1c:

$21.7 \mathrm{kWt}$

18.525 " HPs $\mathrm{U} 235=33 \mathrm{~kg}$

Reactor $=184 \mathrm{~kg}$
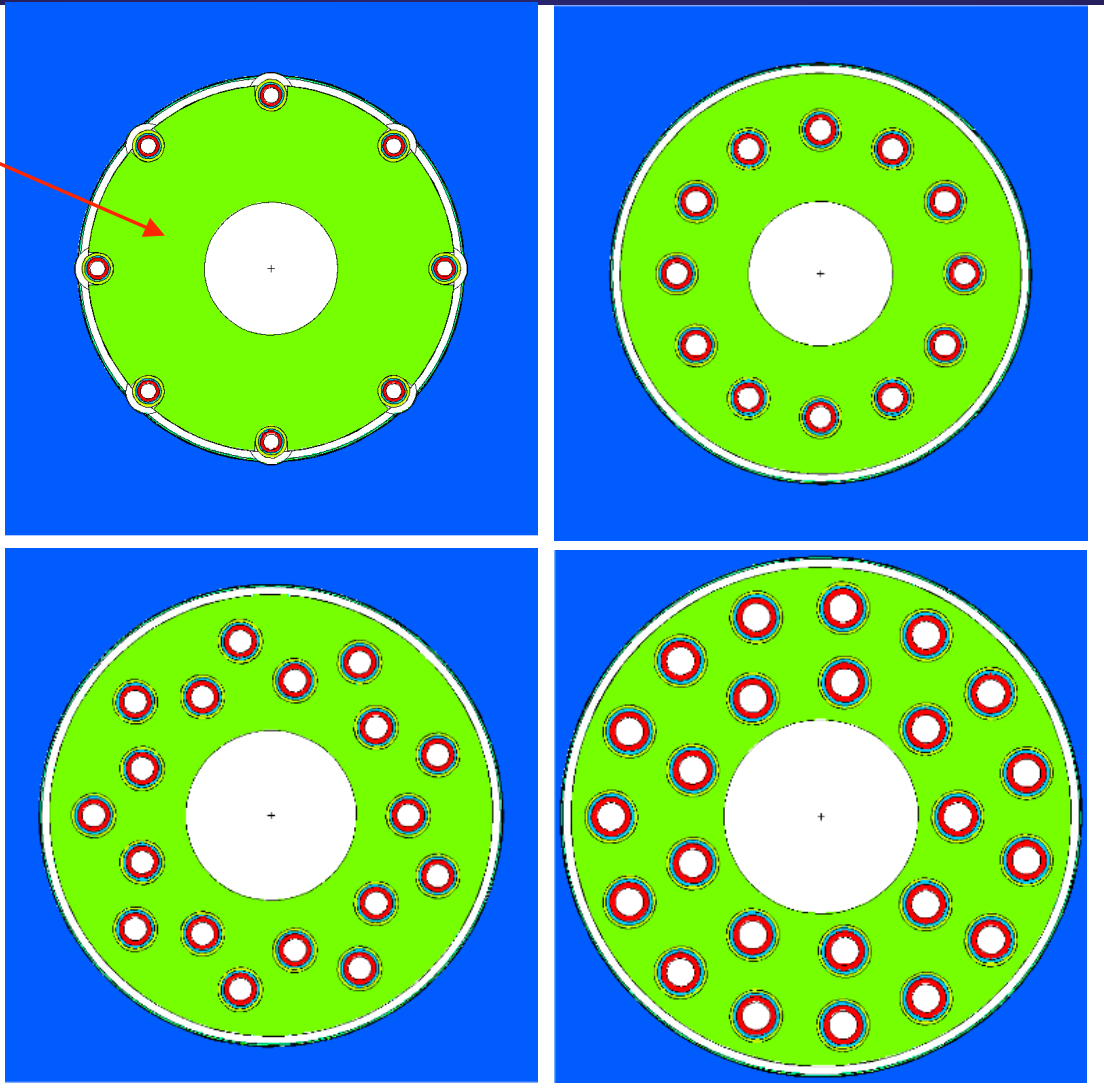

kpwr1b:

$13.0 \mathrm{kWt}$

12 1/2" HPs

$\mathrm{U} 235=30 \mathrm{~kg}$

Reactor $=158 \mathrm{~kg}$

kpwr1d:

$43.3 \mathrm{kWt}$

24 5/8" HPs

$\mathrm{U} 235=43 \mathrm{~kg}$

Reactor 226 kg

Cores are configured so that failed HP peak fuel temp is similar to $4.3 \mathrm{kWt}$ core Nominal fuel temps are actually much lower in the higher power cores (each square is $16 \times 16 \mathrm{~cm}$ ) 


\section{Kilopower / KRUSTY Reactor Differences}

\begin{tabular}{|c|c|c|c|}
\hline & Space 1-kWe Kilopower & KRUSTY & Mars 10-kWe Kilopower \\
\hline Reactivity Control & Central poison rod & Comet lifts reflector & Central poison rod \\
\hline Operating time & 15 years & 48 hours? & 12 years \\
\hline Lifetime Reactivity Control & No & $\mathrm{n} / \mathrm{a}$ & Yes \\
\hline Fuel/radref separation & $1-\mathrm{mm}$ & 1-cm (the Divide) & $1-\mathrm{mm}$ \\
\hline Core can/vessel & No & Yes & Yes \\
\hline Reference heat pipe OD & $3 / 8^{\prime \prime}$ & $1 / 2^{\prime \prime}$ & $5 / 8^{\prime \prime}$ \\
\hline Heat pipe thermal bonding & Clamp force? & Clamp force & Braze? \\
\hline U235 mass & $28.4 \mathrm{~kg}$ & $28.0 \mathrm{~kg}$ & $43.7 \mathrm{~kg}$ \\
\hline Core Length & $24 \mathrm{~cm}$ & $25 \mathrm{~cm}$ & $28 \mathrm{~cm}$ \\
\hline Shielding & LiH/DU shadow & SS/B4C 4pi & SS/B4C 4pi \\
\hline Radref temperature & $\sim 700 \mathrm{~K}$ & $<400 \mathrm{~K}$ & $\sim 700 \mathrm{~K}$ \\
\hline Gravity & $0 \mathrm{~g}$ & $1 \mathrm{~g}$ & $.38 \mathrm{~g}$ \\
\hline Space Qualification & Yes & No & yes \\
\hline Launch safety/approval & Yes & No & yes \\
\hline
\end{tabular}




\section{Notional Timeline - the Big Picture}

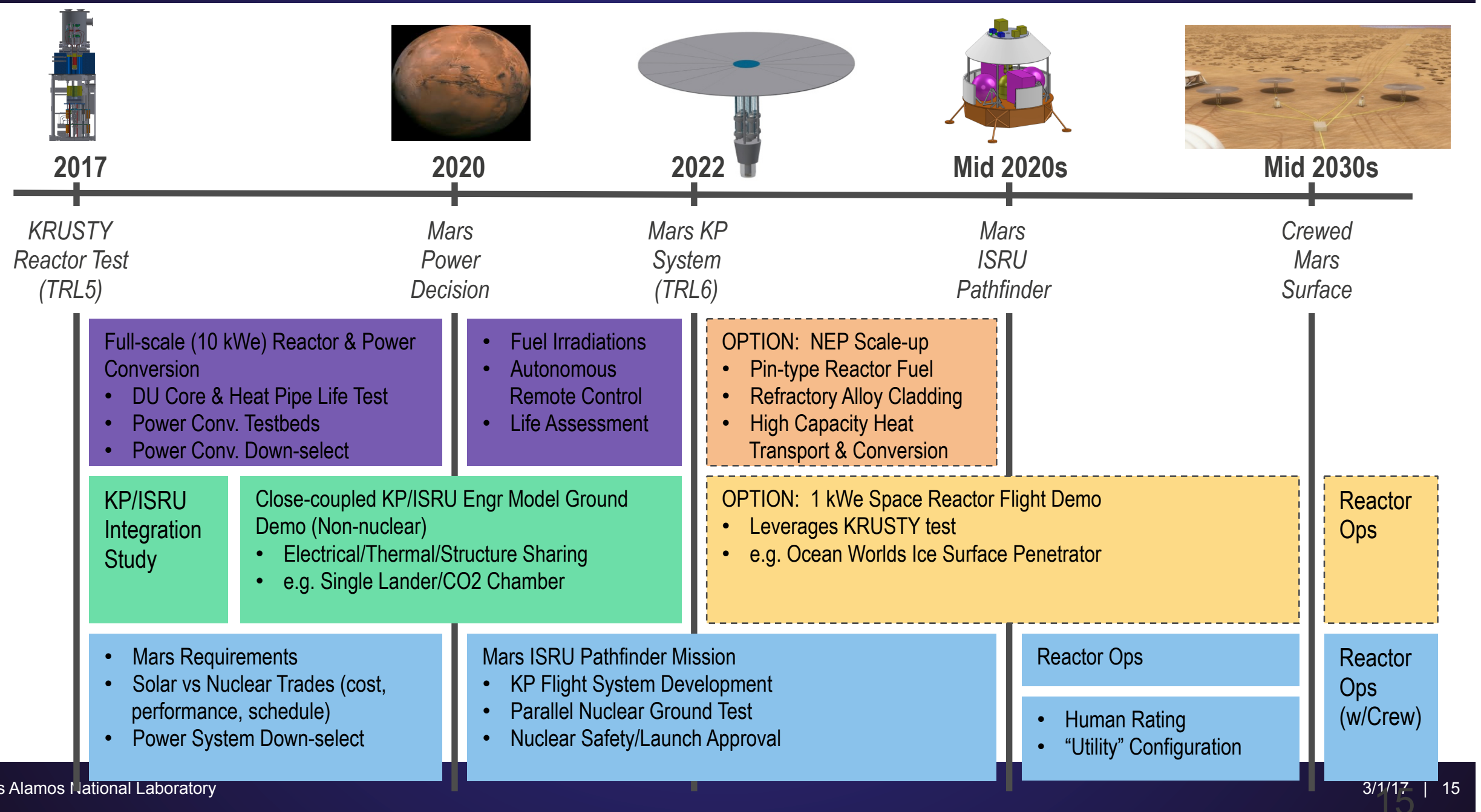




\section{Summary}

- Robust program to develop and deploy a space reactor is in place

- Program is well on the way to delivering a major milestone

- System testing using nuclear fission

- Dave Poston will provide the technical details for the design of the experiment 